\title{
THE LOTTERY-PANEL TASK FOR BI-DIMENSIONAL PARAMETER-FREE ELICITATION OF RISK ATTITUDES
}

\section{EL PANEL DE LOTERÍAS COMO TAREA NO PARAMÉTRICA PARA LA OBTENCIÓN DE LAACTITUD FRENTE AL RIESGO}

\author{
Aurora García-Gallego mgarcia@eco.uji.es \\ Laboratorio de Economía Experimental (LEE). University Jaume I. Castellón. Spain
}

Nikolaos Georgantzís ngeorgantzis@ugr.es

Laboratorio de Economía Experimental (LEE). Universitat Jaume I. Granada Lab of Behavioral Economics (GLOBE). University of Granada. Spain.

AinhOA JARAmillo-GutiéRReZ Ainhoa.Jaramillo@uv.es

Estructura de Recerca Interdisciplinar Comportament Econòmic-Social (ERI-CES)

University of Valencia. Spain

Melanie PaRRavano parrava@correo.ugr.es

University of Granada. Spain

\begin{abstract}
In this paper, we propose a simple task for eliciting attitudes toward risky choice, the Sabater-Grande and Georgantzís (SGG) lottery-panel task, which consists in a series of lotteries constructed to compensate riskier options with higher risk-return trade-offs. Using Principal Component Analysis technique, we show that the SGG lotterypanel task is capable of capturing two dimensions of individual risky decision making: subjects' average willingness to choose risky projects and their sensitivity towards variations in the return to risk. We report results from a large dataset obtained from the implementation of the SGG lottery-panel task and discuss regularities and the desirability of its bi-dimensionality both for describing behaviour under uncertainty and explaining behaviour in other contexts.
\end{abstract}

\section{KEYWORDS}

Decision-making; Lotteries; Psychometric tests; Risk aversion.

\section{RESUMEN}

En este trabajo proponemos una tarea sencilla que permite obtener la actitud frente a la toma de riesgo monetario, y que llamaremos tarea Sabater-Grande y Georgantzís (SGG) de riesgo. Esta tarea consiste en una serie de loterías construidas para compensar las opciones de mayor riesgo con un mayor retorno. Utilizando la técnica de componentes principales, encontramos que la tarea SGG es capaz de capturar dos dimensiones de la toma de decisiones individuales: por un lado, la voluntad promedio de los sujetos de elegir proyectos arriesgados y, por otro, su sensibilidad hacia las variaciones en el retorno por riesgo. Presentamos los resultados de una gran muestra de datos obtenidos a partir de la implementación de la tarea SGG, y discutimos las regularidades y la conveniencia de su bidimensionalidad tanto para describir el comportamiento en condiciones de incertidumbre como para explicar el comportamiento humano en otros contextos.

\section{Palabras clave}

Aversión al riesgo; Loterías; Tests psicométricos; Toma de decisiones. 


\section{INTRODUCTION}

Human beings are usually acting in different contexts and environments. Each individual expresses needs, preferences, attitudes, and ideologies through different actions in each of the domains in which he or she chooses or simply happens to be. As contexts become closer or somehow related to each other, actions by the same individual should also become more related in one way or another. In fact, in an ideal world in which a subjects' personality is a compact and stable system of values and idiosyncratic features, behavior in related contexts should confirm the revelation of the same person. Based on this idea, social scientists like psychologists and economists often try to explain behavior heterogeneity through idiosyncratic differences across subjects. Such differences are usually captured by exposing individuals to decision making tasks or attitude questionnaires. Famous examples are a plethora of intelligence tests and personality inventories used by the psychologists to asses an individual's performing skill and propensity to one or another type of action.

In order to produce reliable tests, it is necessary to invest a substantial amount of effort in (i) developing the task and proposing it to the scientific community, (ii) standardizing the format and applying it among large populations, (iii) generating result distributions by subject category and (iv) identifying successful tasks as reliable approximations of an idiosyncratic factor. Moreover, the search of associations among decisions in different tasks is a main motivator for experimentalists. For example, when studying the effects of intelligence on complex decision making, psychologists correlate scores in, say, Raven (1976)'s Advanced Progressive Matrices (APM), and performance in complex microworlds, like NEWFIRE or COLDSTORE (Rigas, Carling and Brehmer 2002). Beyond the question of what explains what, a systematic rejection of such associations would confine experimental results to the specific setting in which they were obtained, undermining the practical relevance of the research outside the lab. This process is parallel and significantly synergic to the very important endeavor of producing correct theories on the measured aspect itself. However, metaphorically speaking, looking for appropriate tasks in the absence of a perfect theory is like the practice in medicine of establishing clinical protocols for the cure of a disease even before the disease is fully understood.

Paradoxically, economists have failed so far to agree upon the systematic use of a stable task eliciting individual attitudes towards monetary uncertainty. Even the need for external risk measurements is often not recognized by some economists, frequently explaining the effect of risk preferences on observed behavior by theoretically deriving the sufficient conditions for this effect to emerge, thus explaining fact $Y$ by its sufficient

\footnotetext{
*We acknowledge financial support by Bancaixa (P1-1B2010-17) and the Spanish Ministry of Science and Innovation (SEJ2008/04636/ECON). N. Georgantzis gratefully acknowledges financial support by the Junta de Andalucía (P07-SEJ-03155) and the hospitality at LEM, Paris II (France).
} 
(but not necessary) condition $X$ (e.g., Cox and Oaxaca 1996; Goeree, Holt and Palfrey 2002; Campo et al.. 2002). Furthermore, in the few cases in which a task has been used more often than others this has not been done in a systematic way, creating small non comparable samples of observations. Thus, experience and statistical significance have not been built in a cumulative way. Even worse, the so called risk attitude tests are ignoring past evidence and new theories on individual behavior in risky contexts.

In this paper, we propose a decision making task which is specific to individual decision making in contexts involving uncertainty of the monetary consequences of one's actions. Given the importance of uncertainty in modern societies exposed to macroeconomic financial shocks, linking individual attitudes towards risk with actions in other domains would give us a powerful tool to assess the role of personality traits on market functioning. The task discussed in the following pages provides a context for the elicitation of risk attitudes in a way that is both compatible with the need for a multidimensional assessment and robust to alternative mathematical specifications and parameterizations of the model used to organize the data.

The remaining part of the paper is structured as follows: Section 2 reviews economic theories of risky decision making and comments on some devices used to elicit risk attitudes as an external explanatory factor of behavior in other contexts. Section 3 reports results obtained from the application of the lottery-panel test by Sabater-Grande and Georgantzís (2002), SGG. Section 4 concludes. In a longer working paper, we provide more information on the design of the test, as well as instructions for subjects and the experimenter (García-Gallego et al. 2010).

\section{ECONOMIC AND PSYCHOLOGICAL THEORIES AND TESTS OF RISK ATTITUDES}

It is well known that individuals faced with a probability $p$ to earn a given amount of money $x$ may be willing to pay less or more than the product $p \cdot x$ to earn access to this possibility. From a mathematical point of view the product $p \cdot x$ should be used as a certainty equivalent of the aforementioned lottery. Thus, if the probability $p$ of earning $x €$ were evaluated by its mathematical expectation, all people would accept to pay less and would reject to pay more than a certain amount of $p \cdot x €$ in order to participate in the lottery. But, as we know, people are not mathematical machines, nor identical problem solving automata.

An early explanation of why subjects do not evaluate risky choices by their mathematical expectation is attributed to the Expected Utility Theory (EUT) (von Neuman and Morgestern 1944). According to the theory, when comparing a lottery,

$$
\begin{aligned}
L_{1} & =\left(p_{11}, x_{11} € ; \ldots p_{1 n}, x_{1 n} €\right) \\
\text { with } L_{2} & =\left(p_{21}, x_{21} € ; \ldots p_{2 m}, x_{2 m} €\right),
\end{aligned}
$$

where $p_{j i}$ is the probability that the $i$ th best outcome of lottery $j$ occurs, yielding a 
reward of $x_{i j} €$, an agent whose utility is $U(x)$, with $U^{\prime}(*)>0$, will strongly prefer $L_{1}$ to $L_{2}$, as long as

$$
\sum_{i=1}^{n} p_{1 i} \cdot U\left(x_{1 i}\right)>\sum_{i=1}^{m} p_{2 i} \cdot U\left(x_{2 i}\right)
$$

The preference for less risky projects is then explained by a negative second derivative of $U(x)$, implying a decreasing marginal utility from money, a condition often used as synonymous to risk aversion. Despite its survival as the main paradigm in economics as observed by Rabin and Thaler (2001), the EUT was proved to be an incorrect descriptive model since Allais' (1953) paradox, emerging when subjects are faced to alternative lottery pairs with same probability/reward ratios. According to (1), such lotteries should be ranked in the same way, whereas people systematically change their choice in favor of the certain payoff when this becomes part of the feasible set. Kahneman and Tversky (1979) proposed an alternative model, Prospect Theory (PT), assuming that people implicitly use nonlinear weights $w(p)$ to evaluate probabilities. Therefore, in our example, $L_{1}$ would be strongly preferred to $L_{2}$, if:

$$
\sum_{i=1}^{n} w\left(p_{1 i}\right) \cdot U\left(x_{1 i}\right)>\sum_{i=1}^{m} w\left(p_{2 i}\right) \cdot U\left(x_{2 i}\right)
$$

That is, not only the outcomes create non linear utility responses but also probabilities are distorted in the decision maker mind. Therefore, new possibilities emerge concerning what we could expect from a rational decision maker's actions. Consequently, PT accommodates Allais' paradox, whereas it reduces to EUT for $w(p)=p$. Also, observing that losses and gains are processed differently, Tversky and Kahneman (1992) assumed later a power utility function defined separately over gains and losses:

$$
U(x)=x^{a} \text { if } x>0 \text {, and } U(x)=-\lambda(-x)^{b} \text { for } x<0 \text {. }
$$

So $a$ and $b$ are risk aversion parameters, and $\lambda$ is the coefficient of loss aversion. This new version, called Cumulative Prospect Theory (CPT), defines probability weighting over the cumulative probability distributions, offering an explanation of risk-loving behavior for payoffs below their reference point (losses), while exhibiting risk-averse behavior for rewards above their reference point (gains). The form of the probability weighting function proposed by Tversky and Kahneman (1992) has been widely used for both separable and cumulative versions of PT, and assumes weights,

$$
w(p)=p^{\gamma} /\left[p^{\gamma}+(1-p)^{\gamma}\right]^{1 / \gamma}
$$


Therefore, in its simplest formulation, CPT explains risk attitudes using a minimum of four parameters, $a, b, \lambda$ and $\gamma$.

Our overview does not pretend to narrate the history of economic theories of decision making. In fact, we have intentionally omitted heuristics and other theories which cannot be used to propose tasks for the elicitation of risk attitudes. Also, for space reasons we omit the theory proposed by Birnbaum and Navarrete (1998) which can explain violations of stochastic dominance by introducing a third component of risky decision making, namely the attention paid by subjects to the best outcomes among those feasible in a given lottery. We simply want to stress the fact that the evolution of these theories achieves the aim of accommodating phenomena which invalidated earlier theories by the use of more degrees of freedom.

Contrary to this evolution of theories towards more complete and complex descriptions of human behavior in risky environments, all tests currently used are fundamentally uni-dimensional, despite their creation in the post-PT era. This does not mean that all studies of behavior under uncertainty have ignored the multi-dimensional approach dictated by modern theories. In fact, a fruitful line of research has specifically designed and analyzed experimental data to estimate parameters for utility and probability weighting functions, such as the Tversky and Kahneman (1992) probability weighting function and other specifications like, for example, Goldstein and Einhorn's (1987) and Prelec's (1998) two-parameter specification. Furthermore, the nonlinearity of responses to probabilities has even been confirmed at the level of neural responses (Hsu et al. 2009), and, for aversive outcomes (Berns et al. 2008). However, in order to produce ready-to-use data, the elicitation of risk attitudes as an explanatory factor of behavior in another context should not depend on the parameterization or even the theory used. Mapping choices on parameters of utility and probability weighting functions is further complicated by the observation that we may even have to switch between theories in order to account for the heterogeneity observed (Harrison and Rutström 2009).

In recent economic studies, a measure of risk aversion is obtained by the use of the Holt and Laury (2002) HL procedure. Although the task was not, initially, proposed as an external risk-related task to explain behavior in other contexts, it has served this purpose in several occasions (e.g., Goeree, Holt and Palfrey 2003; Lusk and Coble 2005; Harrison, List and Towe 2007; Andersen et al. 2008). Due to its uni-dimensionality, costlessly allowing a one-to-one mapping of choices on specific utility parameters, the test entails a possible loss of information due to under-specification of risk attitudes, which is also likely to reduce its power to explain behavior in other contexts. This is also true for the whole set of alternative procedures used by economists to elicit risk attitudes (e.g., Wakker and Deneffe 1996; Bleichrodt and Pinto 2000; Abdellaoui 2000; Abdellaoui, Bleichrodt and Paraschiv 2007; Hey and Orme 1994; Camerer and Ho 1994; Carbone and Hey 2000; Stott 2006).

The $\mathrm{HL}$ task elicits one individual datum from each block of 10 binary choices, designed to obtain the switching point from a less risky to a more risky alternative. This 
causes a practical problem since some choices do not satisfy the "single-switching" condition. Posterior applications have opted for different solutions to this problem, leading to a variety of alternative implementations which, together with the plethora of designs aimed at identifying other biases of the set up, have created a -undesirable, for our purposes - plethora of non comparable datasets. Contrary to the problem of non comparability among small data sets, several studies (e.g., Wang, Rieger and Hens 2010; Weber and Hsee 1998, 1999) use hypothetical simple questions among large and even international samples, which however have not been used to explain behavior in other contexts.

A broadly used test among psychologists is Zuckerman's (1979) Sensation Seeking Scale (SSS) with which our test exhibits some correlation (Georgantzís et al. 2003). The test is structured as a YES-NO questionnaire on attitudes towards risky activities, under four subscales separating subject's riskiness in different domains, none of which is, strictly speaking, financial. The economic domain of risk is used in the lowa Gambling Task (Bechara et al. 1994). The task was originally aimed at measuring a subject's difficulty to identify the most profitable deck, from which he or she should, thereafter, extract all cards. Using the task as an external risk attitude elicitation device implies significant loss of control, because it mixes risk preferences with a subject's learning ability (a "slow" learner can be confused with a risk loving subject or one with low levels of loss aversion) and it does not fully account for different learning histories. For space reasons, we will not review other tests occasionally used to elicit risk attitudes as an explanatory factor of behavior in other contexts. Rather, we will risk a generalization. All existing tasks suffer from either lack of systematic replication in a stable format generating statistics with large comparable datasets, or they are insufficiently justified as measures of risk attitudes isolated from other parallel phenomena. Furthermore, they are all uni-dimensional.

\section{THE SGG LOTTERY-PANEL TASK}

The SGG lottery-panel task was originally used to study risk preferences parallel to cooperation/competition in prisoner's dilemma games. Riskier subjects were found to be more cooperative. The task consists of four different panels, like those in Figure 1, every one of which contains ten different lotteries. In each lottery, subjects can win a payoff $(x)$ with a probability $(p)$ and otherwise nothing.

Subjects choose (marking the preferred lottery as in the example of Figure 1) one of the ten lotteries from each panel. In the implementation of the task with real money, only one of these four panels, selected randomly at the end of the session, is used to determine a subject's earnings in the experiment. The range of winning probabilities in all panels is the same (from 1 to 0.1 in steps of 0.1 ). The payoff associated to each lottery's winning probability is constructed using the rule: 
Figure 1.

The SGG lottery-panel test and example of subject choices

Panel 1
\begin{tabular}{|l|c|c|c|c|c|c|c|c|c|c|}
\hline Prob. & $\mathbf{1}$ & $\mathbf{0 . 9}$ & $\mathbf{0 . 8}$ & $\mathbf{0 . 7}$ & $\mathbf{0 . 6}$ & $\mathbf{0 . 5}$ & $\mathbf{0 . 4}$ & $\mathbf{0 . 3}$ & $\mathbf{0 . 2}$ & $\mathbf{0 . 1}$ \\
\hline Euros & 1.00 & 1.10 & 1.30 & 1.50 & 1.70 & 2.10 & 2.70 & 3.60 & 5.40 & 10.90 \\
\hline Choice & & & $\mathrm{X}$ & & & & & & & \\
\hline
\end{tabular}

\section{Panel 2}

\begin{tabular}{|l|c|c|c|c|c|c|c|c|c|c|}
\hline Prob. & $\mathbf{1}$ & $\mathbf{0 . 9}$ & $\mathbf{0 . 8}$ & $\mathbf{0 . 7}$ & $\mathbf{0 . 6}$ & $\mathbf{0 . 5}$ & $\mathbf{0 . 4}$ & $\mathbf{0 . 3}$ & $\mathbf{0 . 2}$ & $\mathbf{0 . 1}$ \\
\hline Euros & 1.00 & 1.20 & 1.50 & 1.90 & 2.30 & 3.00 & 4.00 & 5.70 & 9.00 & 19.00 \\
\hline Choice & & & & $\mathrm{x}$ & & & & & & \\
\hline
\end{tabular}

\section{Panel 3}

\begin{tabular}{|l|c|c|c|c|c|c|c|c|c|c|}
\hline Prob. & $\mathbf{1}$ & $\mathbf{0 . 9}$ & $\mathbf{0 . 8}$ & $\mathbf{0 . 7}$ & $\mathbf{0 . 6}$ & $\mathbf{0 . 5}$ & $\mathbf{0 . 4}$ & $\mathbf{0 . 3}$ & $\mathbf{0 . 2}$ & $\mathbf{0 . 1}$ \\
\hline Euros & 1.00 & 1.70 & 2.50 & 3.60 & 5.00 & 7.00 & 10.00 & 15.00 & 25.00 & 55.00 \\
\hline Choice & & & & & & & & $\mathrm{X}$ & & \\
\hline
\end{tabular}

\section{Panel 4}

\begin{tabular}{|l|c|c|c|c|c|c|c|c|c|c|}
\hline Prob. & $\mathbf{1}$ & $\mathbf{0 . 9}$ & $\mathbf{0 . 8}$ & $\mathbf{0 . 7}$ & $\mathbf{0 . 6}$ & $\mathbf{0 . 5}$ & $\mathbf{0 . 4}$ & $\mathbf{0 . 3}$ & $\mathbf{0 . 2}$ & $\mathbf{0 . 1}$ \\
\hline Euros & 1.00 & 2.20 & 3.80 & 5.70 & 8.30 & 12.00 & 17.50 & 26.70 & 45.00 & 100.00 \\
\hline Choice & & & & & & & & & $\mathrm{X}$ & \\
\hline
\end{tabular}

(3) $E\left(L_{i j}\right)=p_{i j} \cdot x_{i j}=c_{j}+\left(1-p_{i j}\right) \cdot t_{j} \Rightarrow x_{i j}=\frac{c_{j}+\left(1-p_{i j}\right) \cdot t_{j}}{p_{i j}}$

$E\left(L_{i j}\right)$ is the expected value of lottery $L_{i j}$, where

$$
i \in\{1,2, \ldots, 10\}
$$

designates one of the 10 lotteries offered in panel

$$
j \in\{1,2,3,4\}
$$

The parameter $c_{j}$ is a constant amount of money which is fixed for this dataset to $1 €$. The parameter

$$
t_{j} \in\{0.1,1,5,10\}
$$

is a panel-specific risk premium, which generates an increase in the lotteries' expected values as we move from safer to riskier options within the same panel. All the panels begin with a sure amount of $1 €$, which is increased as winning probabilities are decreased, resulting in increments of expected values as we move from left to right within each 
panel. These increments are larger as we move from panel 1 to panel 4 . This structure implies that more risk-averse subjects choose lotteries closer to the left of a panel.

Intuitively, this test exposes subjects to the entire range of probabilities and a systematic spectrum of monetary rewards from $1 €$ to the relatively high payoff of $100 €$. At the same time, the test offers a range of different returns to risk so that a more risk averse subject might refuse to take risky options in the first or the second panel, but could be attracted to risky prospects when a high return is offered in panel 3 and 4 . Thus, unlike all uni-dimensional tests, this task may be used to classify subjects not only according to their willingness to take risks, but also with respect to their propensity to change across different risk return combinations. This idea is further developed in the following pages.

In terms of EUT, a subject with constant relative risk aversion (CRRA), as implied in the utility function,

$$
U(x)=\frac{x^{1-r}}{1-r}
$$

makes choices which associate higher risk aversion parameters $r$ to safer choices in each panel, moreover, for a given risk aversion parameter, weakly monotonic transitions towards riskier choices are predicted as we move from panel 1 to panel 4 (GarcíaGallego et al. 2011). All risk neutral and risk loving subjects should choose the lotteries at the far right extreme of the panels.

Considering the fact that with 4 choices the researcher obtains 4 different observations (as opposed to 10 choices for 1 observation in $\mathrm{HL}$ ) per individual subject, we can easily see that the test parsimoniously produces a panel rather than a single column of data. By definition, this corresponds to a multi-dimensional description of individual attitudes towards risk.

\section{A large dataset}

Since its first implementation, the SGG test has been used in several occasions producing various small experimental datasets (e.g., Georgantzís et al. 2003; Brañas-Garza, Georgantzís and Guillén 2007; Brañas-Garza, Guillén and López del Paso 2008; GarcíaGallego et al. 2011). Here, we report results from a large dataset $(N=785)$, obtained between 2003 and 2008, at the Laboratorio de Economía Experimental (LEE, Universitat Jaume I, Castellón-Spain) under comparable conditions, paying special attention to the bi-dimensional nature of decision making and its implications for the explanation of behavior in other contexts. Figure 2 depicts the frequency of choices when all data from all panels are pooled together. Given the variation in prizes and payment methods, this image corresponds to what could be seen as a randomized experiment over the probability space. The peak on the certain payoff captures a certainty effect. A peak on the other extreme $(p=0.1)$ as well as a valley on $p=0.9$ are both compatible with over (under) weighting of small (large) probabilities predicted in PT. Strong attraction of choices towards the "center" $(p=0.5)$ may be the result of subjects' familiarity with 
Figure 2.

Histogram of subjects' pooled probabiity choices across

all panels and implementation conditions

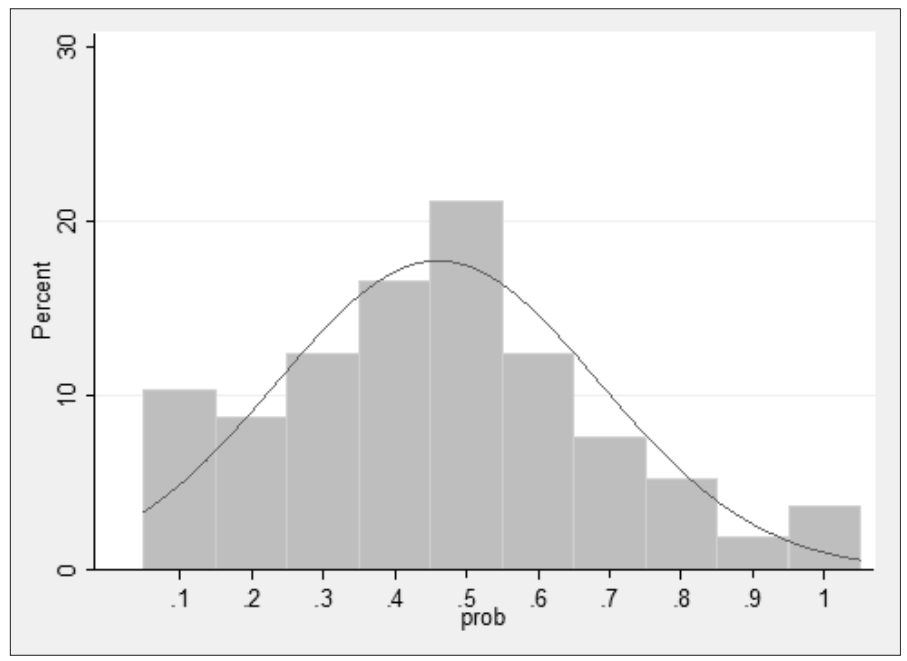

the $p=1 / 2$ probability or simply because of an embedding bias similar to that reported by Bosch-Domènech and Silvestre (2006) on HL. No matter what causes this attraction to the center, this property favors close-to-normal distributions of the resulting variable, making it appropriate for simple OLS regressions.

In Figure 3 we present the same dataset broken down by panel, gender and reward method (hypothetical, $\mathrm{N}=384$; real money, $\mathrm{N}=401$ ). Males are less risk-averse than females. However, males and females behave in more different ways when playing hypothetical lotteries than real ones. Actually, with real rewards, mean choice varies significantly across genders only in panel 3 and 4 (2.7 and 3.9 percentage points at $5 \%$ and $1 \%$ confidence level, respectively). Responsiveness to risk-premium increases, captured by choice variation across panels, is similar for males and females. Specifically, when faced with hypothetical payoffs, both males and females make less risk-averse choices, the higher the reward, while, counterintuitively, when playing with real payoffs, riskier choices are observed in panels with lower risk-returns.

We have argued that it should be a main concern for experimentalists and decision theorists whether a subject's decision under one condition meaningfully relates to behavior under another condition.

Figures 4 and 5 present an aspect of behavior which is missed by other tests. Each graph presents the joint density of individual choices across panel pairs. Each color represents a percentage, i.e. the proportion of subjects whose choice combinations in each panel pair correspond to that specific chart label. Higher risk aversion in one panel 
Figure 3.

Histograms of subjects' probability choices by panel, implementation conditions and gender

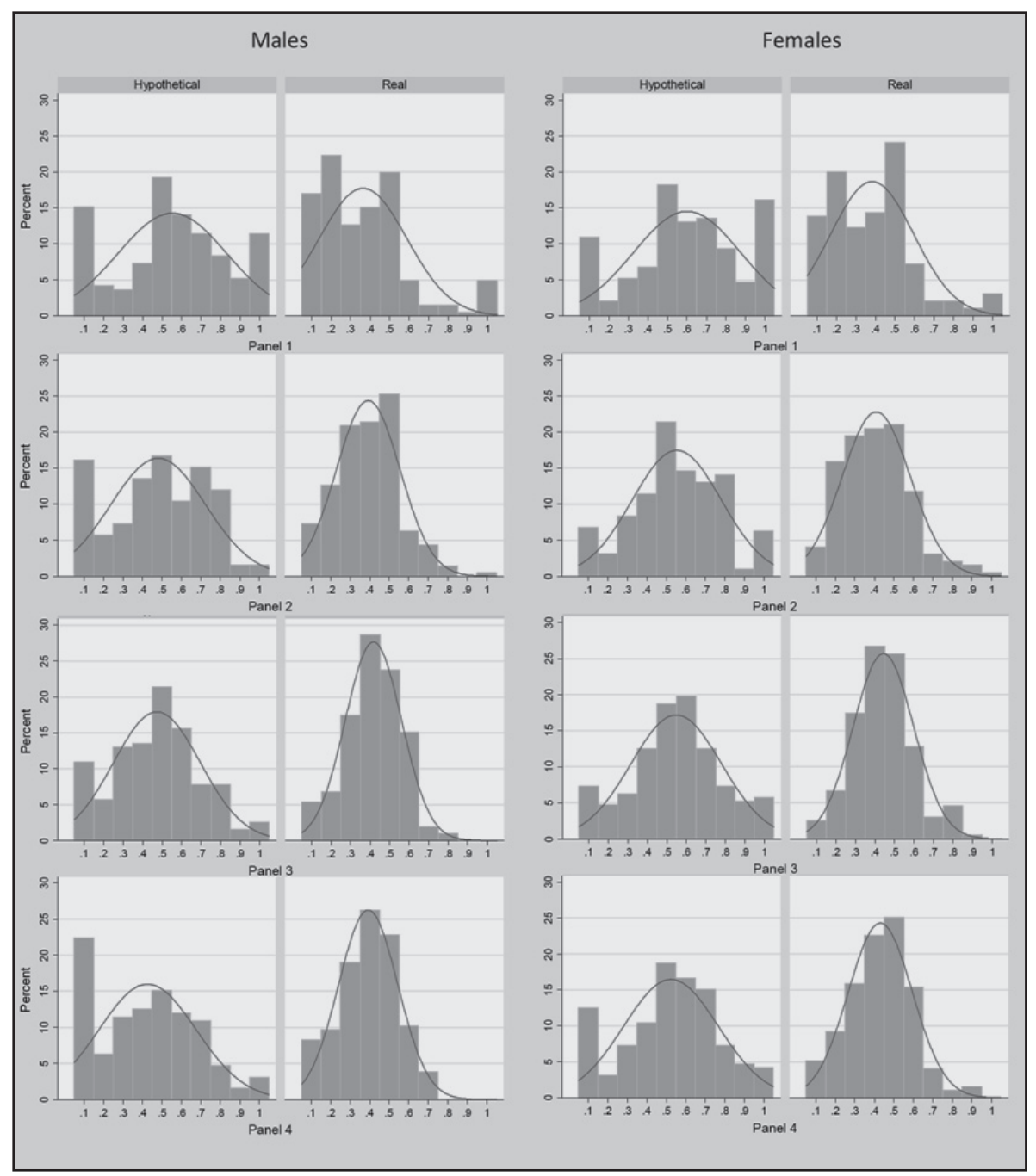


Figure 4.

Subject's choices across panel pairs for hypothetical payoff lotteries. Legend percentage ranges refer to proportion of subjects choosing

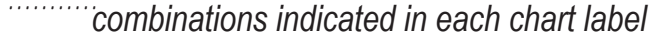

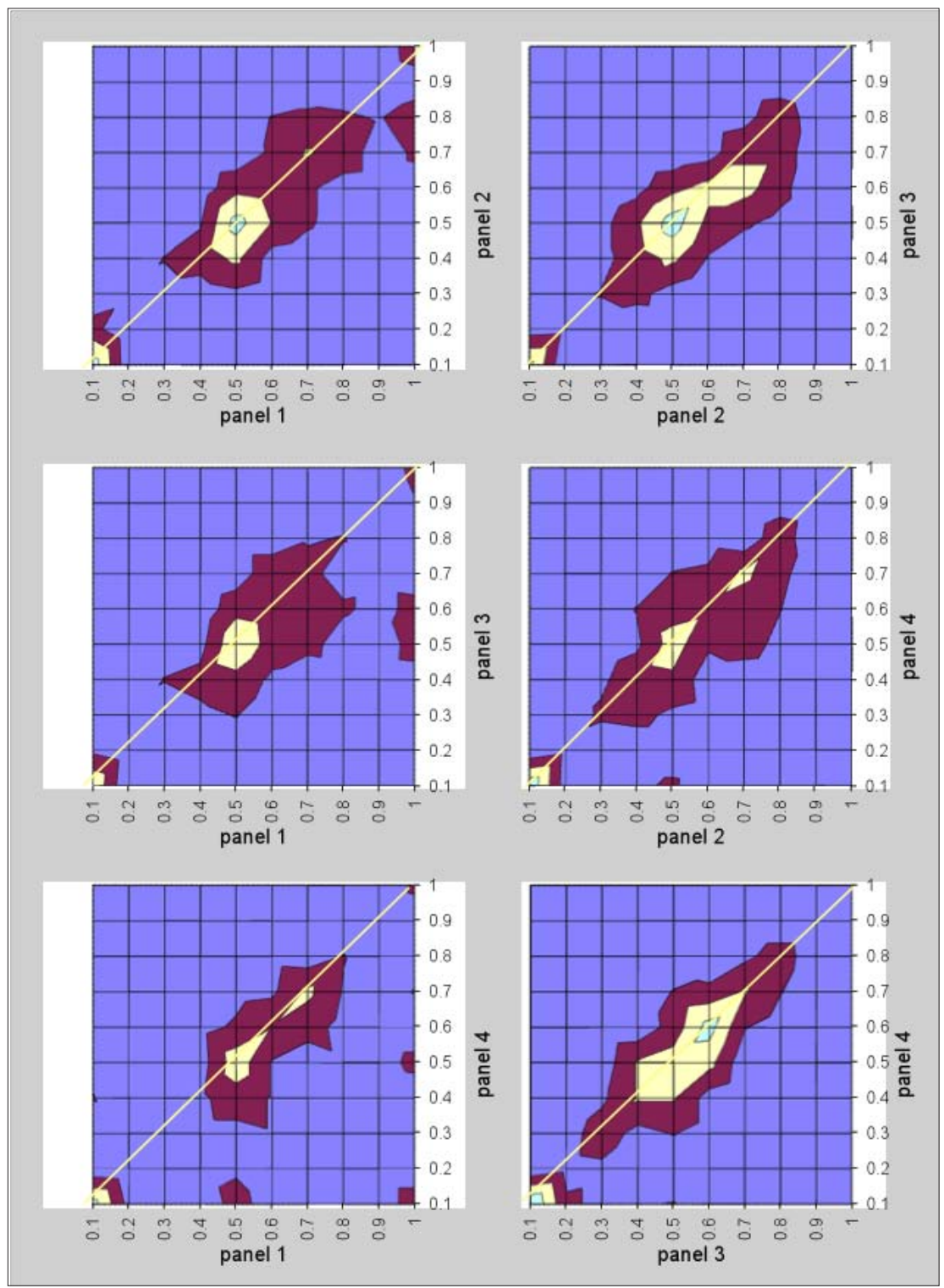


Figure 5.

Subjects' choices across panel pairs for real payoff lotteries. Legend percentage ranges refer to proportion of subjects choosing acasadondcombinations indicated in each chart label

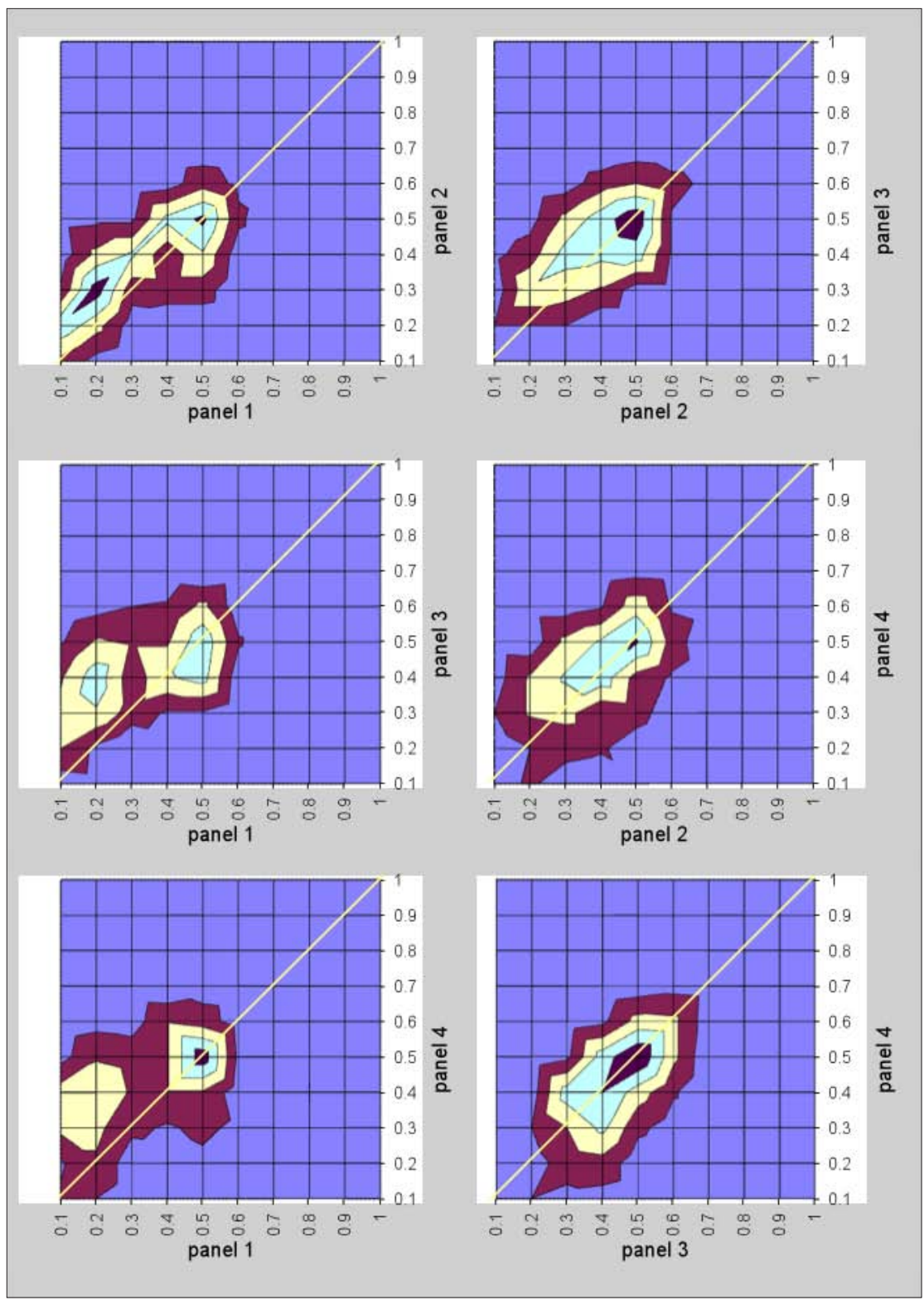


predicts a higher risk aversion in another and, at the same time, reactions to the variation of risk returns across different panels seem to be rather moderate.

As expected, reactions are more visible across more "distant panels", showing that a bigger shock is necessary to guarantee a change of choices. This within-subject pattern reproduces in a more reliable way what we have already observed, namely, that the use of real rewards makes subjects to switch to safer options in the presence of higher returns to risk.

\section{Principal Component Analysis}

It is clear that multidimensional descriptions of risk attitudes require obtaining more than one choice per individual. This is done by the SGG test through the use of the four panels. However we have not shown yet that, first, the additional information obtained significantly improves the description of behavior and, second, that this improvement leads to a higher power of our task to explain behavior in other contexts.

We use Principal Component Analysis (PCA) to construct two synthetic variables (the first two components) capturing $85 \%$ of subjects' choice variance. These variables have the following advantages: (1) they are subject to economic interpretation and, (2) since they are by construction orthogonal among each other, they can be used as explanatory variables of the same model. Intuitively, the first component can be interpreted as an arithmetic mean of choices across the four panels given that the loads of each panel in this component are similar and of the same sign. The second component involves a juxtaposition of panels 1 and 2 on one hand and 3 and 4 on the other, which can intuitively be seen as a measure of sensitivity to risk-premium variations. As observed in Table 1, the component is loaded more by the extreme panel 1 (negatively) and 4 (positively) than by choice differences across the adjacent panels, 2 and 3 . Intuitively, the first component is increasing in the average probability of the lottery chosen in the four panels and can be seen as a standard measure of risk aversion. The second component can be seen as a measure of a subject's sensitivity to variations in the return to risk in the "counterintuitive" direction of lower risk taking in the presence of higher returns to risk. While this confirms our comments on Figures 4 and 5 , it provides a formal motivation for the use of bi-dimensional descriptions of risk attitudes, summarized as individual choice averages and choice variability across contexts (panels).

Using these two components we reconsider gender and hypothetical/real reward effects. It can be seen on Figure 6 that gender differences are specific to the first component, while they diminish or even vanish in the second component. Therefore, males are less risk averse than females but both genders are similar in terms of their sensitivity to variations in the return to risk. Regarding differences between hypothetical and real rewards, both components are relevant. According to the first component, subjects make safer choices in hypothetical lotteries, while, according to the second component they switch more across panels with real rewards, but opposite to the expected pattern of riskier choices for higher risk-returns. 
Table 1.

Cumulative percentages of components eigenvalues (top) and loads per component (bottom)

\begin{tabular}{lccc}
\hline Component & Eigenvalue & Percentage $(\%)$ & Cumulative \% \\
\hline Comp. 1 & $2.742^{* * *}$ & 68.54 & 68.54 \\
Comp. 2 & $0.670^{* * *}$ & 16.75 & 85.29 \\
Comp. 3 & $0.307^{* * *}$ & 7.67 & 92.96 \\
Comp. 4 & $0.282^{* * *}$ & 7.04 & 100 \\
\hline & Panel & Coefficient & Std. Error \\
\hline Comp. 1 & Panel 1 & $0.489^{* * *}$ & 0.016 \\
& Panel 2 & $0.517^{* * *}$ & 0.013 \\
& Panel 3 & $0.521^{* * *}$ & 0.013 \\
& Panel 4 & $0.472^{* * *}$ & 0.017 \\
\hline Comp. 2 & Panel 1 & $-0.577^{* * *}$ & 0.029 \\
& Panel 2 & $-0.372^{* * *}$ & 0.035 \\
& Panel 3 & $0.317^{* * *}$ & 0.036 \\
& Panel 4 & $0.654^{* * *}$ & 0.027 \\
\hline
\end{tabular}

$\left.{ }^{* * \star}\right)$ significant at $1 \%$ confidence level.

\section{Using the SGG test to explain behavior: An example}

García-Gallego et al. (2005) conducted experiments on pricing where firms have some captive clients and they also compete for informed consumers using price comparisons on the Internet. During 50 periods, subjects face the dilemma of setting high prices to benefit from captive clients or lower prices to compete for informed consumers too. Parallel to the main experiment controlling for more and less competitive markets and complete or incomplete price indexing (Treatments T1-T4), the SGG risk elicitation task was implemented with hypothetical rewards.

Following the estimates on Table 2 and abstracting from the specifics of the main experiment, we see that risk attitudes provide significant explanatory power for the pricing behavior observed. In fact, both first and second principal components are necessary to identify the effect of risk attitudes on pricing behavior. On one hand, the first component capturing safe choices is associated to more competitive pricing. That is, more risk-averse subjects set lower prices in order to avoid the risk of not having the lowest price indexed by the engine. On the other hand, the second principal component is also associated with lower pricing. This means that subjects, recognizing the 
Figure 6.

Kernel density estimates for first and second component scores, by gender and reward method

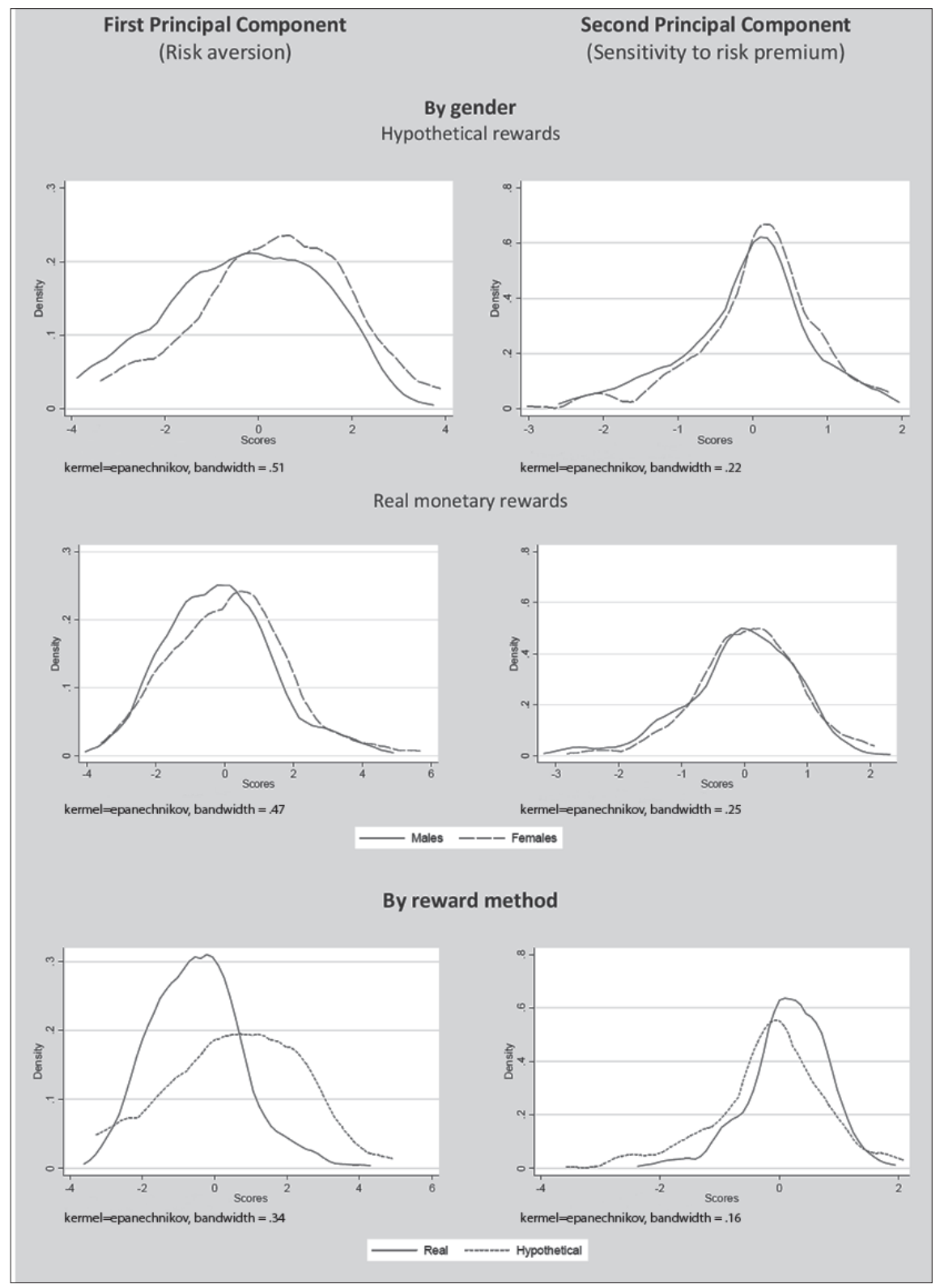


increased profitability of riskier choices across panels, also realize that setting higher prices guarantees profits which do not depend on the excessive randomness of the search process.

Table 2.

Random effects GLS regression: Pricing explained by risk attitudes.

\begin{tabular}{lcc}
\hline \multicolumn{1}{c}{ Dependent variable: price } & & \\
\hline dummy_lose (t-1) & Coefficient & Std. Errors \\
period & $95.09^{* * *}$ & 5.63 \\
dummy_t1 & $-1.55^{* * *}$ & 0.18 \\
dummy_t2 & $73.63^{* * *}$ & 18.54 \\
dummy_t3 & $68.10^{* * *}$ & 18.59 \\
pc1_scores & -4.57 & 18.64 \\
pc2_scores & $-7.54^{*}$ & 4.02 \\
constant & $20.24^{* * *}$ & 6.95 \\
\hline Number of obs $=8820$ & $461.70^{* * *}$ & 14.53 \\
Number of groups = 180 & & \\
\hline Breusch and Pagan LM test for random effects & \\
chi2(1) = 13584.52 & & \\
Prob > chi2 = 0.0000 & & \\
\hline
\end{tabular}

$\left({ }^{*}\right)$ significant at $10 \%$ confidence level, $\left({ }^{* *}\right)$ significant at $5 \%$ confidence level,

$\left.{ }^{(* *}\right)$ significant at $1 \%$ confidence level.

\section{Conclusions}

We have discussed the properties of risk attitudes as captured by the SGG elicitation task. The danger of using uni-dimensional descriptions of risk attitudes goes beyond the incompatibility with modern economic theories like PT, CPT etc., all of which call for tests with multiple degrees of freedom. Faithfull to this prescription, the contribution of this paper is an empirically and endogenously determined bi-dimensional specification of risk attitudes, sufficient to describe behavior under uncertainty and necessary to explain behavior in other contexts. Hopefully, this will assist social scientists to create large datasets containing a multidimensional description of individual risk attitudes, while at the same time it allows for a robust context, compatible with present and even future more complex descriptions of human attitudes towards risk. 


\section{REFERENCES}

Abdellaoui, M. 2000. "Parameter-free elicitation of utility \& probability weighting functions." Management Science 46:1497-1512.

Abdellaoui, M., Bleichrodt, H. and C. Paraschiv. 2007. "Loss aversion under prospect theory: A parameter-free measurement." Management Science 53:1659-1674.

Allais, M. 1953. "Le comportement de l'homme rationnel devant le risque: critique des postulats et axiomes de l'école Américaine." Econometrica 21: 503-546.

Andersen, S., Harrison, G., Lau, M. and E. Rutström. 2008. "Eliciting risk and time preferences." Econometrica 76:583-618.

Bechara, A., Damasio. A. R., Damasio, H. and S.W Anderson. 1994. "Insensitivity to future consequences following damage to human prefrontal cortex." Cognition 50:7-15.

Berns, G. S., Capra, M., Chappelow, J., Moore, S. and C. Noussair. 2008. "Nonlinear neurobiological probability weighting functions for aversive outcomes." Neuroimage 15:2047-2057.

Birnbaum, M. H. and J. Navarrete.1998. "Testing descriptive utility theories: Violations of stochastic dominance and cumulative independence." Journal of Risk and Uncertainty 17:49-78.

Bosch-Domènech, A. and J. Silvestre. 2006. "Risk aversion and embedding bias." Economics Working Papers No. 934. Department of Economics and Business, Universitat Pompeu Fabra. Spain.

Brañas-Garza, P., Georgantzís, N. and P. Guillén. 2007. "Direct and indirect effects of pathological gambling on risk attitudes." Judgment and Decision Making 2(2):126-136.

Brañas-Garza, P., Guillén, P. and R. López del Paso. 2008. "Math skills and risk attitudes." Economics Letters 99:332-336.

Camerer, C. 1989. "An experimental test of several generalized utility theories." Journal of Risk and Uncertainty 2(1):61-104.

Camerer, C. and T. Ho. 1994. "Violations of betweenness axiom and nonlinearity in probability." Journal of Risk and Uncertainty 8:167-196.

Campo, S., Guerre, E., Perrigne, I. and Q. Vuong. 2002. "Semiparametric estimation of first-price auctions with risk averse bidders." Working Paper, University of Southern California.

Carbone, E. and J. Hey. 2000. "Which error story is best?" Journal of Risk and Uncertainty 20:161-176.

Cox, J. C. and R. L. Oaxaca. 1996. "Is Bidding behavior consistent with bidding theory for private value auctions." Pp. 131-148 in Research in Experimental Economics, vol. 6, edited by R.M. Isaac. Greenwich, Conn.: JAI Press.

García-Gallego, A., Georgantzís, N., Pereira, P. and J.C. Pernías-Cerrillo. 2005. "Competing against simulated equilibrium price dispersions: An experiment on Internet-assisted search markets." Working Paper \#5-12, NET Institute. 
García-Gallego, A., Georgantzís, N., Navarro-Martínez, D. and G. Sabater-Grande. 2011. "The stochastic component in choice and regression to the mean." Theory and Decision 71:251-267.

Garcia-Gallego, A., Georgantzís, N., Jaramillo-Gutiérrez, A. and M. Parravano. 2010. "The SGG risk elicitation task: Implementation and results." The Papers 10/04, University de Granada. Spain.

Georgantzís, N., Genius, M., García-Gallego, A. and G. Sabater-Grande. 2003. "Testing for risk return individual decision making." Working Paper 43/03. LINEEX, University of Valencia. Spain.

Goeree, J. K., Holt, C. A. and T. Palfrey. 2002. "Quantal response equilibrium and overbidding in privatevalue auctions." Journal of Economic Theory 104(1):247-272.

Goeree, J., Holt, C. and T. Palfrey. 2003. "Risk averse behavior in generalized matching pennigames." Games and Economic Behavior 45:97-113.

Goldstein, W. and H. Einhorn. 1987. "Expression theory and the preference reversal phenomena." Psychological Review 94:236-254.

Harrison, G., List, J. and C. Towe. 2007. "Naturally occurring preferences and exogenous laboratory experiments: A case study of risk aversion." Econometrica 75:433-458.

Harrison, G. W. and E. Rutström. 2009. "Expected utility theory and prospect theory: One wedding and a decent funeral." Experimental Economics 12(2):133-158.

Hey, J. and C. Orme. 1994. "Investigating generalizations of expected utility theory using experimental data." Econometrica 62:1391-1426.

Holt, C. A. and S. K. Laury. 2002. "Risk aversion and incentive effects." American Economic Review 92(5):1644-1655.

Hsu, M., Krajbich, I., Zhao, C. and C. F. Camerer. 2009. "Neural response to reward anticipation under risk is nonlinear in probabilities." Journal of Neuroscience 29:2231-2237.

Kanheman, D. and A. Tversky. 1979. "Prospect theory: An analysis of decision under risk." Econometrica 47(2):263-292.

Lusk, J. and K. Coble. 2005. "Risk perceptions, risk preference, and acceptance of risky food." American Journal of Agricultural Economics 87:393-405.

Von Neumann and O. Morgenstern, 1944. Theory of Games and Economic Behavior. Princeton University Press.

Prelec, D. 1998. "The probability weighting function." Econometrica 66:497-528.

Rabin, M. and R. H. Thaler. 2001. "Anomalies: Risk aversion." Journal of Economic Perspectives 15(1): 219-232.

Raven, J. C. 1976. Advanced Progressive Matrices. Sets I and II. Oxford: Psychologists Press.

Rigas, G., Carling, E. and B. Brehmer. 2002. "Reliability and validity of performance measures in microworlds." Intelligence 50(5):463-480. 
Sabater-Grande, G. and N. Georgantzís. 2002. "Accounting for risk aversion in repeated prisoners' dilemma games: An experimental test." Journal of Economic Behavior and Organization 48:37-50.

Stott, H. 2006. "Cumulative prospect theory's functional menagerie." Journal of Risk and Uncertainty 32:101-130.

Tversky, A. and D. Kahneman. 1992. "Advances in prospect theory: Cumulative representation of uncertainty." Journal of Risk and Uncertainty 5:297-323.

Wakker, P. and D. Deneffe. 1996. "Eliciting von Neumann-Morgenstern utilities when probabilities are distorted or unknown." Management Science 42(8):1131-1150.

Wang, M., Rieger, M. O. and T. Hens. 2010. "How time preferences differ: Evidence from 45 countries." Research Paper No. 09-47. Swiss Finance Institute.

Weber, E. U. and C. K. Hsee, C. K. 1998. "Cultural differences in risk perception, but cross-cultural similarities in attitudes towards perceived risk." Management Science 44(9):1205-1217.

Weber, E.U. and C. K. Hsee. 1999. "Models and mosaics: Investigating cross-cultural differences in risk perception and risk preference." Psychonomic Bulletin \& Review 6(4): 611-617.

Zukerman, M. 1979. Sensation Seeking: Beyond the Optimal Level of Arousal. New York: Erlbaum Associates.

Aurora García-Gallego is Full Professor at the Economics Department of the University Jaume I (Castellón, Spain). She is co-director and researcher of the Laboratorio de Economía Experimental (LEE) and founding member of the spin-off firm Experimentia Consulting. Her research interests are mainly experimental and behavioural economics. Her work has been published in journals like IJIO, Regional Science and Urban Economics, JEBO, JEMS, Theory and Decision, Environmental and Resource Economics, Ecological Economics or Economics Letters.

Nikolaos Georgantzis is Professor of Economic Theory and Experimental Economics at the Universitat Jaume I (Castellón-Spain), where he founded the Laboratorio de Economia Experimental (LEE). Since 2008, he holds a Research Chair financed by the Junta de Andalucía at the Universidad de Granada, where he founded the experimental economics laboratory EGEO. His research interests include experimental economics and industrial organization.

AinhoA JaRAmiLlo-GutiéRREZ is Lecturer at the at the Department of Applied Economics, University of Valencia, Spain. She is a research member of the Estructura de Recerca Interdisciplinar Comportament Econòmic i Social (ERI-CES) at the University of Valencia and a external researcher of the Laboratorio de Economía Experimental (LEE) in Castellón (Spain). Her main research interests are Game Theory, Microeconomics, Experimental Economics and Industrial Economics.

Melanie Parravano is a PhD Candidate in the program Empirical Economics from the University of Granada, Spain. She holds an BSc in Economics from the University of los Andes, Venezuela, and a Master Degree in Economics from the University of Granada. Her current research interests include Behavioral and Experimental Economics. She is a research fellow of the group of research GLOBE and she is assistant manager of the EGEO experimental economics laboratory of the 
Faculty of Economics and Business, University of Granada. From February 2012 she will join the Centre for Behavioural and Experimental Social Science (CBESS), University of East Anglia, UK.

RECEIVED: 14 July 2011

ACCEPTED: 10 October 2011 